\title{
Football Teams and Levels Supported by University Students
}

\author{
M. Fatih Karahuseyinoglu \\ Correspondence: M. Fatih Karahuseyinoglu, Firat University, Faculty of Sports Sciences, Elazıg, Turkey. \\ Received: February 28, 2019 \\ Accepted: March 24, $2019 \quad$ Online Published: May 15, 2019 \\ doi:10.11114/jets.v7i7.4270 \\ URL: https://doi.org/10.11114/jets.v7i7.4270
}

\begin{abstract}
Football and its propensity have been spread globally, leading to the division/unification of the masses. The prevalence of football in the world has been a source of many researches.

The aim of the study is to determine the football team support levels of the university students and the football teams supported. The research "football team supported by university students and self-defined levels of follow-up ("fanatical", "team supporter" and "football lover") are different, based on the basic hypothesis. The opinion poll developed by the researchers for the purpose of the research consisted of five questions. The data transferred to the computer environment, as a result of the percent, frequency and Chi-Square analyses, provided literature support in the light of scientific data and resulted in general conclusions for the purposes of the research.

The survey, which was developed by the researcher to test the hypothesis of the research, consisted of five questions aimed at determining the gender, age, class, supported football team and support level. They were asked to determine the level of support they considered appropriate after giving information about team support types such as "football lover", "team supporter" and "fanatic". Only their own information is included in the questions. These questions are for the opinions of university students.92) it is high. The data collection tool used in the study is a personal (opinion) data survey, not scale.
\end{abstract}

893 university students attended the study in different departments, $68 \%$ of them were male. $40.4 \%$ of the participants support Galatasaray, $35.5 \%$ support Fenerbahce and $24.1 \%$ support Besiktas teams. The university students who define themselves as fanatic (26.4\%) are less than those who define football fans (37.5\%) and team supporters $(36.1 \%)$.

In a gender-based analysis, it was observed that the ratio of women who define themselves as fanatic was $8.4 \%$ in males and $35 \%$ in females. Different levels of follow-up between women and men are significant when compared to Chi-square analysis.

Among the university students, it was observed that the fans of Galatasaray were more than the others. $28.8 \%$ of the Galatasaray, 27.4\% of the Besiktas Fenerbahceliler 23\% of them identified as fanatic.

Keywords: student, fan, college, football

\section{Introduction}

Football has evolved into a universal phenomenon that has been followed by billions of people in many ways, including mass media and many other ways. Football, which is an important part of everyday life, has become a must for people. The reasons why football is so widespread and mass has been a source of many scientific studies. The most common experience of football tension and joy feelings associated with popular culture today has been transformed into a local, social, National and universal reality by distancing itself from the function of being a pure game (Eker 2010).

The visualness of football, which is visually presented to the service of sports consumers and which cannot be dissolved by mass media for days, even though it is controversial that it is followed or followed for different dimensions and reasons, is indisputable (Appelbaum, et al. 2012). The fact that football is a sport that exceeds universal boundaries and is loved and followed all over the world has allowed it to escape from other sports. In this context, football is now part of the global reality and its reflection is self-evident (Çakır and Korkmaz, 2015). The most basic actor of the football phenomenon is the consumer's follower/supporter/audience. It is difficult to state that football followers are in a homogenous form. However, it is possible to classify spectators in societies where football culture is widely developed. The audience is also undertaking the task of "the twelfth man". Among the main reasons for the implementation of football is the opportunity to deal with the masses in a number of different dimensions. The ways in which football is followed are different from person to person. Football followers/supporters/audience etc. it seems difficult to state that 
they spend time dealing with football in the same activity. It will not be the right approach to handle the spectators who are Team fans and who are upset/happy with the team's defeat/win with the sports fans who are just enjoying the pleasure of the spectators (Ünsal, 2005). It is possible to divide the football team into three parts when evaluated in terms of support styles. They are considered as "football fans" and "fanatics" in the first phase of football team support. These three phases were formed by providing literature support taking into account the different dimensions of football team support. In terms of their characteristics, it is difficult to evaluate the people in the same category as the people who watch a theatre game at least in theater, and also the people who watch football at every stage of their life, who take part in the football game. The concepts of spectators, fanatics and fans are frequently used in the football literature. In this context, those who follow sports activities without any emotional attachment are called fanatics to those who regularly follow and support the teams and athletes that they are interested and those who support the positive feelings towards them are called fanatics (Koruç et al., 2004). In other words, the audience carries only those followers of recreational sports activity, individuals who are integrated with sports teams as a supporter of a city ritual (Taşmektepligil et al. 2015), Fanatic defines individuals who, to an extreme extent, legitimize every way to gain devotion to something with enthusiasm and passion, who are not interested in the aesthetic and beauty of sports, who care about the symbols of their teams at the degree of illness (Püsküllüoğlu, 2001).

When categorically separated, it is possible to glaze soccer followers or followers by more than one person or relative in the form of "soccer lover", "team supporter" and "fanatical". The first stage of football pursuits and only the interest in football, the football lover concept is actually used to express the people who focus on the game itself, albeit a little. It is possible to specify the size of football as the first or most mediocre level of football pursuits (Karahüseyinoğlu M. F: 2015). At this stage, the results of the teams are not very important, but generally the quality of the game and the enjoyment of the game as a viewer are more prominent. Those who follow the rules of the game deliberately or unknowingly criticize referee decisions or player movements from time to time; some focus only on goals because they are score-oriented. It's like the beginning phase of the audience. Neither the joy nor enthusiasm of victory, nor the sorrow of defeat is exaggerated. The next stage is the football supporter; the situation changes according to the previous one, the choice of any football team or party is in question. People in this category have a certain preferences and a sense of belonging. It is the case that any instability. It means being from one side or team in an event or sport. It refers mostly to individuals who are given to the likes of football teams and who support one of the Football teams. The fans are a group of people who know the colors and songs of their team, and people who show that they support the team by wearing a suit in the color of the team to support the team (Acet, 2001). Fans feel like they have won a victory or lost their own game. In other words, the fan's connection with the team is much stronger than the football lover. Supporters are defined as a community that does not only refer to the team supported in sports competitions but also at every moment of daily life, but often forgets the audience to show their interest outside the competition time (Dikici, 2008). Fanaticism is a group of people who can show excessive upset/happy reactions with the success and failure of the team that is blindly connected to the football team supported. People at this stage can't see the truth and the facts, their reactions and behavior are extreme. These reactions and behaviors are very different from the group of supporters with the mouth and body language. Bigotry and conservatism make the eyes of the people in this group so full that they are often not related to the quality of football played. Based on success and failure, a sense of love is important. The football team fanatic is actually expressed as a person who is committed to the football team in a structure that is excessive or excessive (Webster, 1993). He used Latin for the concept of "fanaticus" in the sense that he was inspired by God and was wildly excited and enthusiastic. In this context, football lover, football fan and fanatic, the difference of the concepts to be revealed only with the knowledge of the concepts, details, content and associations can be. Of course, how people position themselves in football, football fan and fanatic concepts are important. However, knowing the contents and connotations of the concepts makes this positioning scientific.

Istanbul teams in Turkey (Hacısoftaoğlu I., Akçan F. Bulgu N) it is known that football clubs rooted in history are Galatasaray, Fenerbahce and Besiktas sports clubs, and that in the historical process the games based on competition are played. Galatasaray, Fenerbahce and Besiktas football clubs, which are recognized as three adults, have exceeded the country's borders. Football follow-up levels in Turkey and the teams supported were evaluated as three seniors and directed to the research.

\section{Material Method}

Students studying the universe of the study in the 2018-2019 academic year, and students in different faculties and classrooms in the 18 and 27 years of age at the University of Firat.

The opinion poll developed by the researchers for the purpose of the research consisted of five questions. The data transferred to the computer environment were analyzed by means of percent, frequency and Chi-Square analyses, and cross-tables were created between the variables considered to be related and interpreted according to their statistical significance $(\mathrm{p}<0.05)$. The scientific data obtained were provided with general conclusions in accordance with the 
aims of the research with the support of the literature and the results of the research were finalized with concrete recommendations.

\section{Finding}

893 students studying in different departments and classrooms participated in the study.

Table 1. Gender

\begin{tabular}{l|c|c}
\hline & n & \% \\
\hline Gender & \multicolumn{3}{|c}{} \\
\hline Woman & 286 & 32,0 \\
\hline Man & 607 & 68,0 \\
\hline Supported Football Teams \\
\hline Galatasaray & 361 & 40,4 \\
\hline Fenerbahce & 317 & 35,5 \\
\hline Besiktas & 215 & 24,1 \\
\hline Total & 893 & 100 \\
\hline
\end{tabular}

$68 \%$ of the students involved in the study are male and $32 \%$ are female. In the supported football team category, the supporters of Galatasaray football club were ranked first with $40.4 \%$, followed by Fenerbahce (35.5\%) and Besiktas (24.1\%) supporters of football clubs.

Table 2. Gender-supported football club analysis table

\begin{tabular}{|c|c|c|c|c|c|c|c|c|c|}
\hline & \multicolumn{2}{|c|}{ Fenerbahce } & \multicolumn{2}{|c|}{ Besiktas } & \multicolumn{2}{|c|}{ Galatasaray } & \multicolumn{2}{|c|}{ Total } & $\begin{array}{c}\text { Chi } \\
\text { Square }\end{array}$ \\
\hline & $\mathrm{n}$ & $\%$ & $\mathrm{n}$ & $\%$ & $\mathrm{n}$ & $\%$ & $\mathrm{n}$ & $\%$ & \multirow{4}{*}{$\begin{array}{l}\chi^{2}: 0,145 \\
\text { df: } 2 \\
\text { p: } 0,93\end{array}$} \\
\hline Woman & 99 & 34,6 & 70 & 24,5 & 117 & 40,9 & 286 & 32,0 & \\
\hline Man & 218 & 35,9 & 145 & 23,9 & 244 & 40,2 & 607 & 66,7 & \\
\hline Total & 317 & 35.5 & 215 & 24.1 & 361 & 40.4 & 893 & 100 & \\
\hline
\end{tabular}

$34.6 \%$ of the women surveyed were Fenerbahce, $24.5 \%$ were Besiktas and $40.9 \%$ were Galatasaray. $35.9 \%$ of male participants are Fenerbahce, 23.9\% are Besiktas and $40.2 \%$ are Galatasaray. There is no significant difference between the women and men in our study.

Table 3. Gender-based team support level analysis table

\begin{tabular}{|c|c|c|c|c|c|c|c|c|c|}
\hline & \multicolumn{2}{|c|}{ Fanatic } & \multicolumn{2}{|c|}{$\begin{array}{c}\text { Team } \\
\text { Supporter }\end{array}$} & \multicolumn{2}{|c|}{$\begin{array}{c}\text { Football } \\
\text { Likes }\end{array}$} & \multicolumn{2}{|c|}{ Total } & Chi Square \\
\hline & $\mathrm{n}$ & $\%$ & $\mathrm{n}$ & $\%$ & $\mathrm{n}$ & $\%$ & $\mathrm{n}$ & $\%$ & \multirow{4}{*}{$\begin{array}{l}\chi^{2}: 97,994 \\
\text { df: } 2 \\
\text { p: } 0,00\end{array}$} \\
\hline Woman & 24 & 8,4 & 97 & 33,9 & 165 & 57,7 & 286 & 32,0 & \\
\hline Man & 212 & 34,9 & 225 & 37,1 & 170 & 28,0 & 607 & 68,0 & \\
\hline Total & 236 & 26.4 & 322 & 36.1 & 335 & 37.5 & 893 & 100 & \\
\hline
\end{tabular}

$33.9 \%$ are team supporters, $57.7 \%$ are fans of football. $34.9 \%$ fanatical of male participants, $37.1 \%$ team supporter, $28 \%$ love football. It is observed that the rate of fanatical in women was $8,4 \%$ whereas the rate of fanatical in men increased to $35 \%$. The number of men who define themselves as Fanatical is higher than women. This difference was considered significant when compared to Chi-square analysis $(\mathrm{p}<0.00)$.

Table 4. The level of support they define themselves according to the supported football club.

\begin{tabular}{|c|c|c|c|c|c|c|c|c|c|}
\hline & \multicolumn{2}{|c|}{ Fanatic } & \multicolumn{2}{|c|}{$\begin{array}{c}\text { Team } \\
\text { Supporter }\end{array}$} & \multicolumn{2}{|c|}{$\begin{array}{c}\text { Football } \\
\text { Likes }\end{array}$} & \multicolumn{2}{|c|}{ Total } & Chi Square \\
\hline & $\mathrm{n}$ & $\%$ & $\mathrm{n}$ & $\%$ & $\mathrm{n}$ & $\%$ & $\mathrm{n}$ & $\%$ & \multirow{5}{*}{$\begin{array}{l}\chi^{2}: 4,142 \\
\text { df: } 4 \\
\text { p: } 0,28\end{array}$} \\
\hline Galatasaray & 104 & 28,8 & 120 & 33,2 & 137 & 38,0 & 361 & 40.4 & \\
\hline Fenerbahce & 73 & 23,0 & 121 & 38,2 & 123 & 38,8 & 317 & 35.5 & \\
\hline Besiktas & 59 & 27,4 & 81 & 37,7 & 75 & 34,9 & 215 & 24,1 & \\
\hline Total & 236 & 26.4 & 322 & 36,1 & 322 & 37,5 & 893 & 100 & \\
\hline
\end{tabular}

Participants participated in the survey, $23 \%$ of the fanatic, $38.2 \%$ of the team supporters, $38.8 \%$ of football fans, 
Besiktas, $27.4 \%$ fanatic, $37.7 \%$ of the team supporters, $34 \%, 9$ football fans, Galatasaray fans, $28.8 \%$ fanatic, $33.2 \%$ team supporters, $38 \%$ have defined themselves as football lovers. Chi-square analysis; the difference was not considered significant.

\section{Discussion and Conclusion}

In order to determine the Football teams and follow-up levels supported by the university students, 893 students were participated in the study between the ages of 18 and 27, according to the different classes of the faculty and Department. Women (32\%) and men (68\%) were supported by the students, respectively; Galatasaray (40.4\%), Fenerbahce (35.5\%), Besiktas $(24.1 \%)$ were ranked from the highest supporter to the minimum. It is possible to find different numbers in different sources when the support of the teams expressed as three adults is evaluated from a numerical point of view. According to a study conducted on the internet in the literature; 36\% of fans in Turkey Galatasaray, 35\% Fenerbahce, 19\% Besiktas were observed to be. (http://tr I'm sorry.beinsports).

This ranking coincides with our work and shows similarity. However, in another study, it is observed that the support of Besiktas Sports Club (46.8\%), Fenerbahce (36\%) and Galatasaray Sports Club (35.9\%) is more (Çağlayan H. S., Fişekçioğlu İ). Especially "three elders" in Turkey (Korukoğlu A., Korukoğlu S.;) the number of supporters of the so-called Istanbul teams differs from each other. When member registration is taken into consideration, different results are obtained. However, although studies have been done on this subject in the literature, there is no clear scientific data to determine the number. Every supporter association expresses itself in high figures. For this reason, it is difficult to find any scientific data in the literature to determine the number, but it has not been found.

Although the percentages of the teams supported by the men and women who did not change in the ranking above were different, this difference was not accepted as significant in the results of the Chi Square analysis (Table 2).

The ratio of the teams of the supporters of the men and women, who are the three elders, to the teams did not change the ranking of Galatasaray, Fenerbahce and Besiktas. Considering the proportion of women's fans to the teams, it is observed that the team with the most women's fans is Galatasaray and then Fenerbahce and Besiktas. In a study conducted by a private research company in 2017 , it was seen that the women supporters of the sports clubs called Three Elders were in similar proportions and similar to our study (https://www.aspor.com.tr).

After the participants were informed about the football team support levels ("football lover", "team supporter" and "fanatical"), they were asked to position themselves, and those who consider themselves "football lover and team supporter" appeared close to each other, but those who define themselves as fanatical are less than others. It was determined that the levels of support levels of university students were similar and that they were not statistically different. $26.4 \%$ of university students see themselves as fanatical. Those who define themselves as football fans $(37.5 \%)$ and Team fans $(36.1 \%)$ are more fanatic than those who see themselves as fanatics (Table 4). When women's support levels are approached with a gender-oriented approach; $33.9 \%$ of the team supporters, $57.7 \%$ of them as football lovers, $37.1 \%$ of men in team supporters, $28 \%$ of them were seen as football lovers. Women who identified themselves as fanatics were $8,4 \%$, while this rate increased to $35 \%$ in males. The different levels of follow-up between women and men were significant when compared to chi-square analysis $(\mathrm{p}<0.00)$. In a different study conducted on the attitudes of different university students who support our study, it is stated that male students are identified with their teams at a higher rate than female students (Gençay S. Karaküçük S). The different forms of support between men and women can be explained by the masculine nature of football and by the fact that it is an area of more interest for men. As a result of the study, it is seen that the team that is the most supportive of university students is Galatasaray. In terms of fanaticism levels, those who define themselves as fanatic among men are more than those who define themselves as fanatic among women. While university students define themselves as a team supporter and a football lover in the same proportions, a small part of them define themselves as fanatic.

\section{Resources}

Acet, M. (2001). Social Factors Directing Football Audience to Be Fanatic and Aggressive, Gazi University Institute of Health Sciences, Ph.D. Thesis, Ankara.

Appelbaum, L. G., Cain, M. S., Darling, E. F., Stanton, S. J., Nguyen, M. T., \& Mitroff, S. R. (2012). What is the identity of a sports spectator? 52(3), 422-427. https://doi.org/10.1016/j.paid.2011.10.048

Çağlayan, H. S., \& Fişekçioğlu, İ. B. (2004). Factors that direct the football audience to violence. Selcuk University Journal of Social Sciences Institute, (12), 127-142.

Çakır, V., \& Korkmaz, S. (2015). Football chants in the context of music and movement. International Journal of Science Culture and Sport, (Special Issue 3), 845-857. https://doi.org/10.14486/IJSCS352

Dikici, S. T. (2008). Fans in the social and political profile in Turkey: Besiktas Bazaar group instance. Kocaeli 
University, Institute of Social Sciences, Master Thesis.

Eker, G. Ö. (2010). Irressistable, Portrait of Fascinated Supporter, Fanaticism and Besiktas. National Folklore Magazine; 22(85), 173-183

Gençay, S., \& Karaküçük, S. (2006). A Research on the Behaviors of University Students Related to Sports Fans. Gazi Journal of Physical Education and Sports Sciences, XI(4), 11-22.

Hacısoftaoğlu, İ., Akçan, F., \& Bulgu, N. (2015). Fan communities as fictitious communities; Example of Ankaragucu fans groups. Sport sociology studies beyond the game. Not your parents publishing. Ankara.

http: //tr.beinsports.com/haber/en-cok-taraftar-kimde (access date; 13/02/2019).

https: //www.aspor.com.tr/galeri/diger/turkiyede-en-cok-taraftar-hangi-taki me (access date: 13.02.2019).

Karahüseyinoğlu, M. F. (2015). Sports Sociology, Introduction to Sports Sciences, (edit: Erdal Demir), Nobel Publishing, Istanbul.

Koruç, Z., Bayar, P., \& Arslan, F. (2004). Football fanatics in Turkey: Social identity and violence. Football Association of Turkey in Ankara branch of the man and the General Directorate of Sports Toto terror Football Competition Causes and Prevention Ways Scientific Research Competition. Ankara.

Korukoglu, A., \& Korukoglu, S. (2005). The Situation of the Three Elders in the Banking, FB and GS Financial Markets. Ege Academic Review Journal, 5(1), 47-54.

Püsküllüoğlu, A. (2001). Dictionary of foreign words in Turkish. 2. Printing. Friend Publications. Ankara.

Richmond, R. L., Kehoe, L., \& Webster, I. W. (1993). Weight change after smoking cessation in general practice. Medical journal of Australia, 158(12), 821-822. https://doi.org/10.5694/j.1326-5377.1993.tb137670.x

Taşmektepligil, M. Y. Y., Çankaya, S., \& Taner, T. O. (2015). Football Fan Fan Scale. Journal of sport and Performance Studies, 6(1), 41-49.

Ünsal, A. (2005). Tribune community's anger: Turkey commercialization of football violence, Communication Publications.

\section{Copyrights}

Copyright for this article is retained by the author(s), with first publication rights granted to the journal.

This is an open-access article distributed under the terms and conditions of the Creative Commons Attribution license which permits unrestricted use, distribution, and reproduction in any medium, provided the original work is properly cited. 